\title{
Patients' Cardiac Self-Efficacy After Coronary Artery Angioplasty
}

\author{
Arsalan Salari, ${ }^{1}$ Leila Rouhi Balasi, ${ }^{2,}{ }^{*}$ Fatemeh Moaddab, ${ }^{2}$ Fatemeh Zaersabet, ${ }^{2}$ Azam Nouri Saeed, ${ }^{3}$ and \\ Samaneh Habib Nejad ${ }^{1}$ \\ ${ }^{1}$ Department of Cardiology, Guilan Interventional Cardiovascular Research Center, Heshmat Hospital, Guilan University of Medical Sciences, Rasht, IR Iran \\ ${ }^{2}$ Department of Medical Surgical Nursing, Guilan Interventional Cardiovascular Research Center, Heshmat Hospital, Guilan University of Medical Sciences, Rasht, IR Iran \\ ${ }^{3}$ Department of Psychology, Islamic Azad University, Rasht, IR Iran \\ "Corresponding author: Leila Rouhi Balasi, Department of Medical Surgical Nursing, Guilan Interventional Cardiovascular Research Center, Heshmat Hospital, Guilan \\ University of Medical Sciences, Rasht, IR Iran. Tel: +98-9119312905. E-mail: roohi_balasi@yahoo.com
}

Received 2016 February 19; Revised 2016 March 05; Accepted 2016 March 15.

\begin{abstract}
Background: The patients undergoing coronary artery angioplasty should be motivated to adhere to lifestyle modifications. One of the factors affecting this issue is cardiac self-efficacy. Cardiac self-efficacy motivates individuals to select a lifestyle related to their cardiovascular diseases through creating the desire to adjust with such behaviors.

objectives: The current research aimed to determine the cardiac self-efficacy predictors after coronary artery angioplasty.

Patients and Methods: In this cross-sectional study, 193 patients undergoing coronary artery angioplasty in Dr. Heshmat educational therapeutic center were selected through convenience sampling. The data were collected by a questionnaire consisted of two sections, including socio-demographic factors and cardiac self-efficacy after oral consent of the subjects. Then data were analyzed via descriptive (frequency distribution, mean and standard deviation) and inferential statistics (Pearson, ANOVA and independent t-test). To define cardiac self-efficacy predictors, multi-linear regression model was applied.

Results: Based on the obtained results, the mean age of subjects was $58.35 \pm 9.97$ years, the majority were male (60.6\%) and the underlying diseases history (57.5\%) and the mean time interval between repeated angioplasty was $17.48 \pm 25.2$ months. Also the mean score of cardiac self-efficacy among these patients was $8.43 \pm 4.5$. Also, based on the results of the statistical tests, there was a significant relationship between age $(\mathrm{P}<0.001)$, gender $(\mathrm{P}=0.024)$, education $(\mathrm{P}<0.0001)$, hypertension history $(\mathrm{P}=0.006)$, living conditions $(\mathrm{P}=0.03)$, job $(\mathrm{P}=0.001)$ and monthly income $(\mathrm{P}=0.003)$ with cardiac self-efficacy. As the multi-linear regression test results suggested, age was the only cardiac self-efficacy predictor.

Conclusions: The current study results implied low cardiac self-efficacy score in the study units; then it is recommended to consider care plans to improve the cardiac self-efficacy.
\end{abstract}

Keywords: Coronary Artery Disease, Self-Efficacy, Angioplasty, Patients

\section{Background}

Cardiovascular diseases are identified as one of the most significant causes of death. Also, the prevalence of cardiovascular diseases in Iran is seriously increasing. Therefore in Iran, 39.9\% of deaths are due to these diseases that can be considered as the main cause of death (1), among which coronary artery disease (CAD) is the most important one (2); hence, around 17 million people have the disease (1). Some CAD treatment methods are coronary artery bypass surgery (CABG) and coronary angioplasty (2). Cardiac catheterization and percutaneous coronary intervention (PCI) are the common invasive methods to diagnose and treat cardiac diseases and $\operatorname{CAD}(3,4)$. These methods are successful in minimizing heart damage, limiting heart failure extent and decreasing coronary artery disease induced deaths (3). Generally, the patients undergoing PCI underestimate their CAD and have the wrong belief that during this short period of hospitalization and quick method, they are completely treated (4).

Not observing the recommended instructions is identified as a cause behind unfavorable outcomes and increased health care costs; especially the subjects with cardiovascular diseases acknowledge that (5). Many patients do not observe the recommended lifestyle changes (6). Thus, those with CAD are in need of boosting their empowerment skills in order to effectively control their symptoms and prevent the disease induced complications. One way to raise the individual's capability is to build up their selfefficacy (7).

Bandura defines self-efficacy as the person's beliefs in his capabilities to succeed in special situations $(1,6,8,9)$. This theory suggests that the individuals' beliefs about their capabilities predict their behavioral performance (1, 10). In fact, an individual's self-efficacy level determines his thinking, feeling, behavior and motivation (11). There- 
fore, if the patients do not believe their capabilities to improve their health condition through changing behavior and drug taking for all their life time, it is not possible to achieve this goal (12). Self-efficacy stabilizes the condition of patients and helps them to effectively cope with stress and CAD induced stress (1). Generally speaking, working on promoting self-efficacy and empowering them is important in self-care regimen follow-up through selfefficacy promotion (13). It is depicted that self-efficacy affects health and health-related outcomes based on the behaviors in treating the patients with chronic diseases and is considered as one of the most significant predictors of behavioral modifications in the patients $(4,14,15)$. On the other hand, self-efficacy is directly associated with healthy behaviors and indirectly influences healthy behaviors to achieve the goals, the challenges the individuals are facing and perseverance, commitment and effort to reach the goal (16).

Cardiac self-efficacy is indeed an exclusive cardiac scale about an individual's belief about his capabilities to do the activities related to CAD symptoms and challenges $(1,14$, 17). Cardiac self-efficacy motivates the individuals to select a lifestyle about their cardiovascular disease via creating enthusiasm to adjust with such behaviors (14). The studies indicated that the individuals with high self-confidence actively participate in health promoting health plans (4, 16). Therefore, low self-efficacy with low self-esteem is pessimistic thinking about oneself and lack of decent performance. High self-efficacy is associated with active coping strategies, searching social support and problem solving (optimism) (18).

It should be mentioned that the role of self-efficacy is proved at the beginning and maintaining health behaviors and observing treatment in other chronic diseases such as type 2 diabetes (19). Self-efficacy is a critical factor influencing management of risk factors in the primary and secondary cardiovascular disease prevention. Virtually, in the individuals with higher self-efficacy, it is more probable to cooperate for risk reducing behaviors and following designed treatment interventions to lower cardiac disease risk factors $(2,20)$. It seems that determining the cardiac self-efficacy predictors can help the medical staff to identify the patients' self-efficacy promoting factors in order to take measures to boost health behaviors, self-management and as a result improve life quality.

\section{Objectives}

The current research aimed to determine the cardiac self-efficacy predictors after coronary artery angioplasty.

\section{Patients and Methods}

\subsection{Research Environment and Patients}

The population of this cross-sectional study included the patients undergoing coronary artery angioplasty in Dr. Heshmat medical-educational hospital in Rasht, Iran, in 2015. Based on the results of the study by Kang et al. (20) and confidence level of $95 \%$ the sample size of the study was defined 193 patients, selected by the convenient sampling method out of the people who had angioplasty at least six months ago referring to the Dr. Heshmat specialized clinic. The inclusion criteria were lack of psychological and mental diseases based on the patient's record and asking the patient about the history of taking antipsychotic drugs, doing angioplasty for the first time and at least six months passing it and patients were excluded if they did not have the inclusion criteria (Equation 1).

$n=\frac{\left(Z_{1-\frac{\alpha}{2}}\right)^{2} \times \sigma^{2}}{d^{2}}$

\subsection{Questionnaire}

Data collection was conducted through interview based on a questionnaire. The study questionnaire consisted of two sections including socio-demographic variables and cardiac self-efficacy scale. In the current research, in order to determine cardiac self-efficacy, Sullivan 5-item cardiac self-efficacy scale was applied, where each answer is assigned 5 scores based on the Likert scale and finally, self-efficacy scores from 0 to 20 and higher scores imply better self-efficacy to maintain performance (21). To validate this scale, the professionals in the field were polled and the results in all expressions suggested that CVR and CVI were over $75 \%$. To establish the tool reliability, test retest results showed the correlation between the two steps $92 \%$, denoting the tool expressions reliability.

\subsection{Ethical Considerations}

Before data gathering, the ethics committee of Guilan University of Medical Science (proposal code: 93100813) approved the study. Also, data collection was conducted after explaining the research objective to the patients and obtaining their oral consent.

\subsection{Statistical Analysis}

The collected data were analyzed using descriptive statistics (frequency distribution, mean and standard deviation) and inferential statistics (Pearson, ANOVA and independent t-test) after determining normal distribution of variables by Kolmogorov Smirnov test by SPSS ver. 16. Pearson test was employed to determine the relationship between the two quantitative variables. ANOVA was used to 
compare the mean score of cardiac self-efficacy in three or more groups and independent t-test to compare the scores in the two groups. Also $\mathrm{P}<0.05$ was considered significant. Then to determine self-efficacy predictors, multi-linear regression model was used.

\section{Results}

The current study results showed that the mean age of the subjects was $58.35 \pm 9.97$ years. The majority of the subjects were male (60.6\%), married (92.2\%), illiterate (45.6\%) and housewives (35.2\%). The majority had hypertension (56.9\%) and the underlying diseases history (57.5\%), but no diabetes (92.7\%). The mean time interval between repeated angioplasty was $17.48 \pm 25.2$ months.

The research results displayed that the mean score of cardiac self-efficacy in the patients was $8.43 \pm 4.5$. In addition, the statistical results showed a significant relationship between age $(P<0.0001)$, gender $(P=0.024)$, patient education level $(\mathrm{P}<0.0001)$, hypertension history $(\mathrm{P}=$ $0.006)$, life conditions ( $P=0.03)$, job $(P=0.001)$ and cardiac self-efficacy. But there was no significant relationship between marital status, family history of CAD, the underlying diseases history, coronary artery disease duration, and cardiac self-efficacy.

The multi-linear regression test results suggested that age was the only cardiac self-efficacy predictor. Therefore, younger age can be a better cardiac self-efficacy predictor (Table 1).

\section{Discussion}

The current study results indicated that the patients undergoing coronary artery angioplasty had low cardiac self-efficacy score. The research by Boroumand et al. (22) titled "analyzing self-efficacy and its related factors in patients with ischemic heart disease" showed that the majority of the patients had high self-efficacy and the study by Jalilian et al. (18) aimed to analyze the general self-efficacy and the perceived social support influencing the life quality of patients with cardiovascular disease showed that units had average self-efficacy. The reason behind these inconsistent findings can be the difference of the tools applied in the studies. Therefore, regarding several studies indicating a significant relationship between self-efficacy and health promoting behaviors such as diet, exercise, pharmaceutical compliance, quitting alcohol and smoking and weight control, it seems essential to take some measures to enhance self-efficacy in such patients because it facilitates the keen feeling of competency, cognitive process and health behaviors (4). On the other hand, empowering the person with coronary artery problem for self-care can prevent the disease complications and /or delay its outbreak (7).

The multi-linear regression results only depicted age as a cardiac self-efficacy predictor. Therefore, the findings revealed a significant statistical and reverse relationship between age and cardiac self-efficacy. This finding was in line with that of the study by Saveh et al. (23) aimed to discover self-efficacy status among patients with heart failure in Kurdistan province of Iran and also its related factors and how it was associated with self-care in the patients. The current research demonstrated that self-efficacy in younger age was higher and gradually by getting older, this level lowered. Of course, the results of the study by Paryad et al. (7), analyzing the self-efficacy of patients with coronary artery and its predictors and the research by Jeans titled "describing self-efficacy role, determining the role of self-efficacy, goal setting behaviors, health related quality of life, psychosocial factors and health care utilization in post-inpatient rehabilitation cardiac patients" (2), also stated this finding. While in the study by Parkinson et al. (11), titled "cardiac rehabilitation outcome psychosocial factors predictors", no significant relationship was found between age and cardiac self-efficacy. It seems that by getting older, besides reduced physical capabilities, selfefficacy drops in the patients with ischemia; in addition, age increase is a factor that affects getting other chronic diseases and this issue influences lowered confidence compared with the disease personal control (22).

The limitations of the study included small sample size, non-random sampling method and the use of selfreported method for data gathering.

Unfortunately, the current study results indicated low cardiac self-efficacy score in the study units suggesting the requirement of the interventions to improve self-efficacy, since self-efficacy was a critical behavior predictor and acted as an independent part of individuals' basic skills (24) and it can play an important role in the individuals' health promotion and disease complications prevention and symptoms recurrence. Thus by training self-efficacy skills and self-control of internal-external stresses, it is possible to pave the ground for raising the general health and life quality of patients with cardiovascular disease (16).

\section{Acknowledgments}

Authors wish to appreciate Guilan Medical University research and technology department and Guilan cardiovascular international research center and all the patients cooperating in the study. 
Table 1. Regression Coefficient Factors Associated With Cardiac-Efficacy Score Based on Multi-Linear Regression

\begin{tabular}{|c|c|c|c|c|c|c|}
\hline \multirow[t]{2}{*}{ Predictor variable } & \multirow[t]{2}{*}{$\mathrm{B}$} & \multirow[t]{2}{*}{$\mathbf{S E}^{\mathbf{a}}$} & \multirow[t]{2}{*}{$\mathbf{P}$} & \multirow[t]{2}{*}{$\operatorname{EXP}(\beta)$} & \multicolumn{2}{|c|}{ 95.0\% C.I. for EXP (B) } \\
\hline & & & & & Lower & Upper \\
\hline Age & 0.167 & 0.07 & 0.02 & 0.328 & 0.308 & 0.027 \\
\hline Gender & 3.044 & 1.639 & 0.069 & 0.242 & 6.334 & 0.247 \\
\hline Patients' level of education & 0.528 & 0.647 & 0.418 & 0.114 & 0.770 & 1.826 \\
\hline Hypertension history & 1.113 & 1.201 & 0.358 & 0.110 & 1.297 & 3.523 \\
\hline Life conditions & 0.529 & 1.130 & 0.642 & 0.059 & 2.797 & 1.740 \\
\hline Job & 0.208 & 0.412 & 0.615 & 0.072 & 0.619 & 1.035 \\
\hline
\end{tabular}

${ }^{\mathrm{a}} \mathrm{SE}$, standard error.

\section{Footnotes}

Authors' Contribution: Arsalan Salari: the study design and conception; Leila Rouhi Balasi: the manuscript draft and data analysis; Fatemeh Moaddab: data analysis; Fatemeh Zaersabet: the study conception; Azam Nouri Saeed: the study design and data collection; Samaneh Habibnejad: data gathering.

Funding/Support: This study was funded by Interventional Cardiovascular Research Center in Guilan University of Medical Sciences in Iran.

\section{References}

1. Varaei S, Shamsizadeh M, Cheraghi MA, Talebi M, Dehghani A, Abbasi A. Effects of a peer education on cardiac self-efficacy and readmissions in patients undergoing coronary artery bypass graft surgery: a randomized-controlled trial. Nurs Crit Care. 2014 doi:10.1111/nicc.12118.

2. Janes SG. A description of the role of self-efficacy, goal setting behaviors, health related quality of life, psychosocial factors, and health care utilization in post-inpatient rehabilitation cardiac patients. Spalding University; 2010.

3. Shiloh S, Steinvil A, Drori E, Peleg S, Abramowitz Y, Banai S, et al. Effect of guidance during cardiac catheterization on emotional, cognitive and behavioral outcomes. J Cardiovasc Med. 2014;15(4):336-42. doi: 10.2459/JCM.ob013e3283613925.

4. Son YJ, Kim SH, Park JH. Role of depressive symptoms and self-efficacy of medication adherence in Korean patients after successful percutaneous coronary intervention. Int J Nurs Pract. 2014;20(6):564-72. doi: 10.1111/ijn.12203.

5. Gehi AK, Ali S, Na B, Whooley MA. Self-reported medication adherence and cardiovascular events in patients with stable coronary heart disease: the heart and soul study. Arch Inter Med. 2007;167(16):1798-803.

6. Peterson JC, Link AR, Jobe JB, Winston GJ, Marina Klimasiewfski E, Allegrante JP. Developing self-management education in coronary artery disease. Heart Lung. 2014;43(2):133-9. doi: 10.1016/j.hrtlng.2013.11.006. [PubMed: 24373484].

7. Paryad E, Hosseinzade T, Kazemnejad E, Asiri S. A Study of Self-efficacy in Patients with Coronary Artery Disease and Its Predictors [in Persian]. Qom Univ Med Sci J. 2013;7(2):41-8.

8. Steca P, Greco A, Cappelletti E, D’Addario M, Monzani D, Pancani L, et al. Cardiovascular Management Self-efficacy: Psychometric Properties of a New Scale and Its Usefulness in a Rehabilitation Context. Ann Behav Med. 2015;49(5):660-74.
9. Wang LW, Ou SH, Tsai CS, Chang YC, Kao CW. Multimedia Exercise Training Program Improves Distance Walked, Heart Rate Recovery, and Self-efficacy in Cardiac Surgery Patients. J Cardiovasc Nurs. 2015:17. doi: 10.1097/JCN.0000000000000246.

10. Al-Khawaldeh OA, Al-Hassan MA, Froelicher ES. Self-efficacy, selfmanagement, and glycemic control in adults with type 2 diabetes mellitus. J Diabetes Complications. 2012;26(1):10-6. doi: 10.1016/j.jdiacomp.2011.11.002. [PubMed: 22226484].

11. Parkinson CRL. Psychosocial Predictors of Cardiac Rehabilitation Outcome. United States: Rosalind Franklin University of Medicine and Science; 2014.

12. Baljani E, Rahimi J, Amanpour E, Salimi S, Parkhashjoo M. Effects of a nursing intervention on improving self-efficacy and reducing cardiovascular risk factors in patients with cardiovascular diseases [in Persian]. Hayat. 2011;17(1):45-54.

13. Savadkooh O, Zakerimoghadam M, Gheyasvandian S, Kazemnejad A Effect of Self-Management Program on Self-Efficacy in Hypertensive Patients [in Persian]. J Mazand Univ Med Sci. 2012;92(2):18-28.

14. O Neil A, Berk M, Davis J, Stafford L. Cardiac-self efficacy predicts adverse outcomes in coronary artery disease (CAD) patients. Health. 2013;58(7):6-14

15. Maeda U, Shen BJ, Schwarz ER, Farrell KA, Mallon S. Self-efficacy mediates the associations of social support and depression with treatment adherence in heart failure patients. Int J Behav Med. 2013;20(1):88-96. doi: 10.1007/s12529-011-9215-0.

16. Moghadam B, Yarian S, hosseini S, Mohammad Hosseini S. Predicting the quality of life based on public health, social support and self efficacy in cardiovascular patients [in Persian]. Armaghane-danesh. 2014;19(7):633-42.

17. Fors A, Ulin K, Cliffordson C, Ekman I, Brink E. The Cardiac Self-Efficacy Scale, a useful tool with potential to evaluate person-centred care. Eur J Cardiovasc Nurs. 2015;14(6):536-43. doi: 10.1177/1474515114548622. [PubMed: 25149667].

18. Jalilian M, Mostafavi F, Sharifirad G. Relationship between Selfefficacy, perceived social support and quality of life in patient's with cardiovascular disease: A cross-sectional study [in Persian]. J Health Syst Res. 2013;9(5):531-9.

19. Rajati F, Sadeghi M, Feizi A, Sharifirad G, Hasandokht T, Mostafavi F. Self-efficacy strategies to improve exercise in patients with heart failure: A systematic review. ARYA Atheroscler. 2014;10(6):319-33. [PubMed: 25815022].

20. Kang Y, Yang IS. Cardiac self-efficacy and its predictors in patients with coronary artery diseases. J Clin Nurs. 2013;22(17-18):2465-73. doi: 10.1111/jocn.12142. [PubMed: 23441807].

21. Sarkar U, Ali S, Whooley MA. Self-efficacy and health status in patients with coronary heart disease: findings from the 
heart and soul study. Psychosom Med. 2007;69(4):306-12. doi: 10.1097/PSY.0b013e3180514d57. [PubMed: 17510290].

22. Boroumand S, Shahriari M, Jebeli MA, Baghersad Z, Baradaranfard F, Ahmadpoori F. Determine the level of self-efficacy and its related factors in patients with ischemic heart disease: A descriptive correlational study [in Persian]. Iran J Nurs Res. 2015;9(5):61-9.
23. Saveh MB, AshkTorab T, Farahani ZBA, Zayeri F, Anboohi SZ. The relationship between self-efficacy and self-care behaviors in chronic heart failur [in Persian]. Nurs Midwifery J. 2012;78(2):17-26.

24. Rajati F, Mostafavi F, Sadeghi M, Sharifirad G, Feizi A, Mohebi S. Exercising Self-Efficacy in Patient with Heart Failure: A Review Study [in Persian]. J Health Syst Res. 2013;8(6):929-41. 